\title{
INDUSTRY-DRIVEN AREA-WIDE MANAGEMENT OF QUEENSLAND FRUIT FLY IN QUEENSLAND AND NEW SOUTH WALES, AUSTRALIA: CAN IT WORK?
}

\author{
H. KRUGER \\ School of Sociology, Research School of Social Sciences, Australian National \\ University, CanberraACT 2601, Australia; heleen.kruger@agriculture.gov.au
}

\begin{abstract}
SUMMARY
Queensland fruit fly, Bactrocera tryoni (Froggatt) (Tephritidae), is one of Australia's most problematic and costly horticultural pests. As key insecticides traditionally used to manage the pest have recently been restricted, area-wide management (AWM) of Queensland fruit fly is becoming a key recommended practice. The increased push for AWM coincides with several state governments reducing direct on-ground support for pest management. It is increasingly up to local industries to take the reins of implementing AWM programmes. This study explored the social and institutional aspects of industry-driven AWM to understand how these programmes can best be supported. The findings are based on AWM case studies in Queensland and New South Wales in Australia, as well as interviews with people who operate in Australia's broader fruit fly management innovation system. The findings reported here complement the prevailing techno-centric emphasis relating to Queensland fruit fly management. They are summarised in five principles: (i) the local social profile influences the prospects of successful AWM; (ii) AWM needs to be based on adaptive co-management; (iii) local industries need help to help themselves; (iv) AWM programmes in Queensland need strong two-way connectivity with the broader Queensland fruit fly management innovation system; and (v) industry-driven AWM programmes need institutional adjustment to share public roles and responsibilities. These principles are discussed, as well as their policy implications. The study concludes that industry-driven AWM is only possible in certain circumstances.
\end{abstract}

Key Words: Bactrocera tryoni, Tephritidae, community support, enabling environment, institutional design, fruit flies, social factors, fruit industry, horticulture, stakeholder involvement, adaptive comanagement, international trade Development and Field Application, pp. 693-708. CRC Press, Boca Raton, Florida, USA. (C) 2021 IAEA 


\section{INTRODUCTION}

In various countries there is an increasing push for local agricultural industries to be less dependent on direct government support and take on more responsibility for pest management (Higgins et al. 2016). One such pest in Australia is the Queensland fruit fly (Bactrocera tryoni (Froggatt)), which is established throughout parts of eastern Australia (Clarke et al. 2011). Queensland fruit fly is a particularly problematic pest as most fruit and vegetables are susceptible to infestation to varying degrees. Queensland fruit fly numbers can quickly soar under favourable conditions and the pest has the ability to cause considerable damage to crops (Dominiak and Ekman 2013). The pest can therefore have a huge economic impact, especially as several of Australia's horticulture international trading partners place costly requirements or restrictions on produce from Queensland fruit fly-infested areas (PHA 2008). In addition, the application of two key chemical insecticides that were traditionally used to manage the pest, fenthion and dimethoate, have been restricted (Dominiak and Ekman 2013).

Area-wide management (AWM) is seen as a key alternative Queensland fruit fly management strategy (NFFC 2016; PHA 2008). It promises a reduced need for insecticides and is acknowledged in international trade regulations as an acceptable phytosanitary approach for fruit fly (FAO 2016). However, many regions face reduced direct on-ground government support for Queensland fruit fly management resulting from cuts in pest monitoring and treatment activities, and extension services. Local industries now need to drive collaboration between various stakeholder groups and risk contributors (such as landholders with Queensland fruit fly hosts on their land) in order to initiate and maintain AWM programmes.

Responsibility for the management of Queensland fruit fly is addressed across a federated system involving delegated people in various organizations and roles. These organizations include the Australian Government, which oversees international trade matters that are affected by Queensland fruit fly. State/territory governments are responsible for providing support for Queensland fruit fly suppression and domestic market access impacted by Queensland fruit fly. Various public and private organizations conduct Queensland fruit fly-related research. Several recent initiatives were introduced to address the Queensland fruit fly problem, including the National Fruit Fly Council, the National Fruit Fly Research, Development and Extension Plan (PBCRC 2015), and the establishment of a Sterile Insect Technique consortium (SITplus). As these initiatives occurred after the initial field work of this research, their impact on the results presented here was limited.

This paper contains a summary of the key findings of a $\mathrm{PhD}$ project that investigated the social and institutional aspects of industry-driven Queensland fruit fly AWM in Australian horticulture industries, with special focus on three case studies in the states of Queensland and New South Wales. Traditionally, pest management has predominantly been approached as a technical issue in need of technical solutions (Schut et al. 2014). This chapter complements this techno-centric thinking. 


\section{METHODS}

The study involved mixed methods research and included qualitative interviews and focus groups (facilitated small group discussions), and a quantitative grower survey. In phase 1 (2013-2014) an assessment was made of how the success of industry-driven AWM can be bolstered at the local on-ground level. It comprised three case studies (Table 1), together with a review of scholarly literature about socio-ecological systems (e.g. Ostrom 2005; Armitage et al. 2008) and community-based natural resource management (such as Berkes 2010; Klerkx et al. 2012; Curtis et al. 2014).

The online grower survey, involving the same three case study areas, was carried out between phases 1 and 2 towards the end of 2015. For a more detailed summary of the phase 1 methods see Kruger (2016a, 2016b).

In phase 2 (2015-2016), ways were identified to create an enabling environment for industry-driven AWM, i.e. the conditions needed that will support local industries to take the lead in AWM programmes. This was done both in terms of Queensland fruit fly suppression and market access. It involved 33 interviews with people operating in the broader fruit fly management innovation system (Table 2).

Table 2. An overview of the people interviewed in phase 2 about how to create an enabling environment for industry-driven fruit fly $A W M$

\begin{tabular}{|c|c|}
\hline Organizational background & Number of interviewees \\
\hline${ }^{\mathrm{c}}$ \\
\hline State government \\
\hline - Queensland fruit fly researcher & 7 \\
\hline - Policy & 6 \\
\hline - Industry support & 4 \\
\hline - Operational management & 1 \\
\hline Australian Government - Policy & 3 \\
\hline University & 2 \\
\hline Industry body & 7 \\
\hline Local industry & 2 \\
\hline Local government & \\
\hline Consultant & 3 \\
\hline
\end{tabular}

${ }^{a}$ New South Wales and Queensland only

${ }^{b}$ Five others were interviewed during phase 1 (see Table 1)

${ }^{c}$ Some interviews involved more than one interviewee

These findings, together with the grower survey results, were analysed by applying agriculture innovation systems thinking (Klerkx et al. 2012; Schut et al. 2014). Such thinking sees innovation as a co-evolutionary process involving not only technical, but also social and institutional change that results in on-ground progress (Klerkx et al. 2012). For a more detailed summary of the phase 2 methods see Kruger (2017). For a detailed explanation of the full PhD study's methods see Kruger (2018). 
Table 1. Overview of the three AWM (area-wide management) case studies investigated, including for each case study information about the areas they cover, the number of growers, kinds of crops produced, local support for AWM, indicators of success, factors that enable or hinder AWM, and the data collected from these regions (adjusted from Kruger 2016a)

\begin{tabular}{|c|c|c|c|}
\hline & Central Burnett (Queensland) & Riverina (New South Wales) & Young-Harden (New South Wales) \\
\hline $\begin{array}{l}\text { Local Govern- } \\
\text { ment Areas }{ }^{\mathrm{a}}\end{array}$ & $\begin{array}{l}\text { Along the Burnett River within the North Burnett } \\
\text { Region Local Government Area }\end{array}$ & $\begin{array}{l}\text { Local Government Areas of Carrathool, Griffith, Leeton, } \\
\text { Murrumbidgee, Narrandera }\end{array}$ & $\begin{array}{l}\text { Local Government Areas of Young and } \\
\text { Harden }\end{array}$ \\
\hline No. of growers & $40{\text { (2016 - mainly citrus })^{b}}^{b}$ & $\begin{array}{l}\text { Approx. } 420^{\mathrm{b}} \text { citrus; } 372^{\mathrm{b}} \text { grape; } 55^{\mathrm{b}} \text { prune, and many other } \\
\text { growers of horticultural crops (2014) }\end{array}$ & Approx. $35^{\mathrm{b}}$ cherry, $20^{\mathrm{b}}$ grape (2015) \\
\hline $\begin{array}{l}\text { Crops produced } \\
\text { and areas } \\
\text { involved }\end{array}$ & $\begin{array}{l}2,266 \mathrm{ha}^{\mathrm{c}} \text { citrus (mainly mandarins); } 370 \text { ha table } \\
\text { grapes (2010) }\end{array}$ & $\begin{array}{l}8,133 \mathrm{ha}^{\mathrm{c}} \text { citrus; } 7,200 \text { ha vegetables; } 15,000 \text { ha grapes; } 1,365 \\
\text { ha walnuts; } 885 \text { ha prunes; } 300 \text { ha cherries; and smaller } \\
\text { plantings of other hosts (approx. } 30,000 \text { ha of horticulture) }\end{array}$ & $\begin{array}{l}\text { Estimated } 650-700 \mathrm{ha}^{\mathrm{b}} \text { cherries; and up } \\
\text { to } 1,000 \mathrm{ha}^{\mathrm{b}} \text { of wine grapes }\end{array}$ \\
\hline $\begin{array}{l}\text { Support for } \\
\text { AWM }\end{array}$ & $\begin{array}{l}\text { - All growers implement rigorous Queensland fruit fly } \\
\text { baiting }\end{array}$ & $\begin{array}{l}\text { - The local citrus industry pushes for broad-scale Queensland } \\
\text { fruit fly management to support market access }\end{array}$ & $\begin{array}{l}\text { - Cherry industry pushes for AWM to } \\
\text { support market access }\end{array}$ \\
\hline & $\begin{array}{l}\text { - Growers voluntary fund town treatments, but } \\
\text { contributions are dwindling }\end{array}$ & $\begin{array}{l}\text { - Other horticultural industries show little interest as Queensland } \\
\text { fruit fly does not affect them economically }\end{array}$ & $\begin{array}{l}\text { - Grape growers are less engaged as } \\
\text { unaffected economically by fruit fly }\end{array}$ \\
\hline $\begin{array}{l}\text { Indicators of } \\
\text { AWM success }\end{array}$ & $\begin{array}{l}\text { - Successful Queensland fruit fly suppression in season } \\
\text { - Queensland fruit fly management practices led to } \\
\text { protocol ICA-28, increasing domestic market access }\end{array}$ & - Too early to tell & - Too early to tell \\
\hline Factors enabling & - Trust relationships between growers and consultants & - Cold winters & \\
\hline AWM & $\begin{array}{l}\text { - Small industry } \\
\text { - Growers have similar on-farm objectives } \\
\text { - Small, horticulture-dependent towns }\end{array}$ & $\begin{array}{l}\text { - Some packing houses insist that their grower suppliers provide } \\
\text { proof of Queensland fruit fly management through spray } \\
\text { records and receipts of fruit fly management inputs }\end{array}$ & $\begin{array}{l}\text { - Cold winters } \\
\text { - Strong local government support } \\
\text { Small industry }\end{array}$ \\
\hline $\begin{array}{l}\text { Factors hindering } \\
\text { AWM }\end{array}$ & $\begin{array}{l}\text { - Lack of enforcement mechanism to sustain grower } \\
\text { contributions for town treatments } \\
\text { - Queensland fruit fly is endemic } \\
\text { - Disappointment with inaccessibility to overseas } \\
\text { markets without cold treatment contributes to } \\
\text { dwindling grower contributions for town treatments }\end{array}$ & $\begin{array}{l}\text { - Many horticulture growers with multiple on-farm objectives } \\
\text { - Lack of representative leadership } \\
\text { - Many part-time, low-input growers } \\
\text { - Large/medium-sized towns dependent on multiple industries } \\
\text { - No local power to enforce cooperation } \\
\text { - Lack of communication channels to all horticulture growers }\end{array}$ & $\begin{array}{l}\text { - Medium-sized towns } \\
\text { - Little local power to enforce } \\
\text { cooperation } \\
\text { - Limited local communication and } \\
\text { influence across all horticulture } \\
\text { growers }\end{array}$ \\
\hline Qualitative data & $\begin{array}{l}\text { - Thirteen interviews } \\
\text { - One focus group } \\
\text { - October } 2013\end{array}$ & $\begin{array}{l}\text { - Twenty interviews } \\
\text { : One focus group } \\
\text { : March } 2014\end{array}$ & $\begin{array}{l}\text { - Nine interviews }{ }^{\mathrm{d}} \\
\text { - One focus group } \\
\text { September } 2013\end{array}$ \\
\hline $\begin{array}{l}\text { Grower survey } \\
\text { response rate }\end{array}$ & $\begin{array}{c}70 \% \\
(28 / 40)^{\mathrm{e}}\end{array}$ & $\begin{array}{c}51 \% \\
(50 / 98)^{\mathrm{e}}\end{array}$ & $\begin{array}{c}63 \% \\
(20 / 32)^{\mathrm{e}}\end{array}$ \\
\hline
\end{tabular}




\section{FINDINGS AND DISCUSSION}

Fig. 1 represents the consolidation of the key findings of the $\mathrm{PhD}$ research, and shows that AWM programmes can be conceptualised as comprising three key components that stretch across various levels of activity:

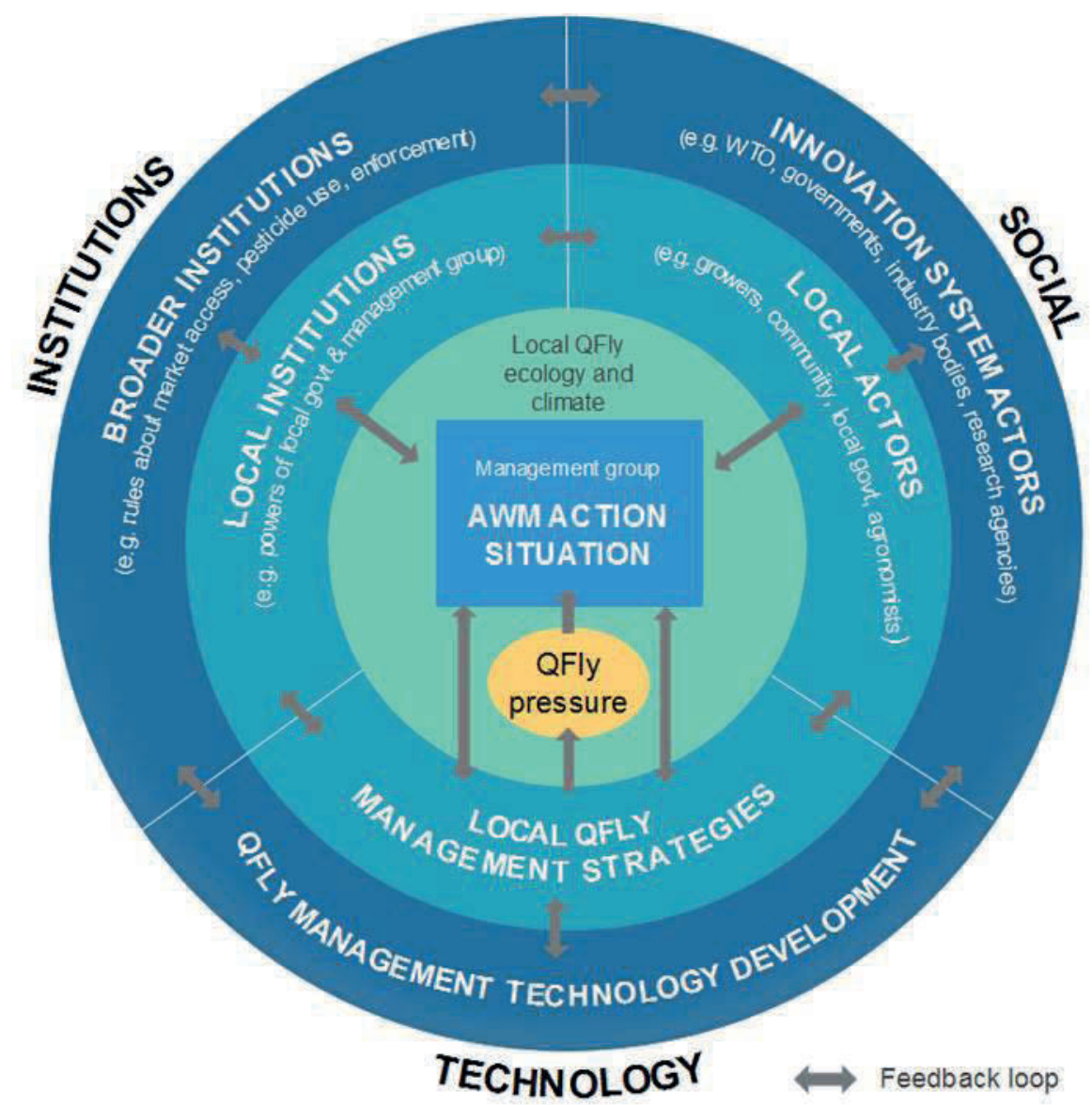

Figure 1. Conceptualised fruit fly management innovation system that will enable industrydriven AWM.

- Social - people and groups at local, state, national and international levels whose actions, interactions and decisions (or lack thereof) can either facilitate or hinder AWM.

- Institutions - formal (laws, regulations, standards) and informal (norms and accepted behaviour) that apply at local, state, national and international levels that influence the design and implementation of AWM. 
- Technology - Queensland fruit fly-related technologies and information that are available at the local level and flow predominantly from the broader fruit fly management innovation system that stretches across state, national and international levels.

Following agriculture innovation systems thinking, each AWM programme is therefore embedded in a broader innovation system at higher levels comprising social, institutional and technological components that influence the feasibility of industrydriven AWM programmes.

The two-way arrows in Fig. 1 emphasise the importance of multi-directional information flow across levels and between the three key components. This is necessary to ensure that the different components are responsive to each other.

The key findings can be summarised in the following five principles that are also reflected in Fig. 1. A detailed explanation of the study's findings is contained in Kruger (2018).

\subsection{Principle 1. The Local Social Profile Influences the Prospects of Successful $A W M$}

With the international drive for harmonised phytosanitary measures, the impact due to the uniqueness of different local regional communities on their ability to achieve AWM can be easily underestimated. This research found four social variables that determine the degree of difficulty to achieve AWM, i.e. the transaction cost to develop local institutions (formal and informal rules) that support AWM that are widely supported by risk contributors (Kruger 2016b).

First variable: High heterogeneity of the contributors to Queensland fruit fly risk complicates setting local rules, such as identifying who needs to implement fruit fly management, what is required from them and how to win their commitment. Different on-farm objectives, pest impacts and market requirements for Queensland fruit fly management make it harder to identify a common AWM objective. For example, in the Riverina area in New South Wales, a small proportion of citrus growers is interested in exporting to premium Queensland fruit fly-sensitive markets. However, a large proportion is comprised of part-time growers supplying the domestic juice market. As their horticultural operations are not their primary income source, it lessens their incentive to participate in AWM, whereas exporters would like to see fruit fly management implemented to a high standard. Moreover, a heterogeneous mix of grower sectors means that the local AWM management group needs to establish trust and communication channels with more diverse stakeholders. This can challenge the management group's legitimacy and credibility across the region.

When stakeholder investment is not proportionate to the distribution of eventual benefits, they might view any or some rules as unfair, which discourages cooperation (Ostrom 2005). Identifying who will gain most, and therefore who ought to contribute most, is not always initially evident. For example, AWM is seen as a good candidate to be included in systems approaches for trade, e.g. applying at least two independent risk management measures that cumulatively achieve acceptable levels of pest risk (Dominiak and Ekman 2013; FAO 2018). However, in practice many markets remain wary of accepting systems approaches and achieving AWM may not necessarily 
render post-harvest treatments, such as cold sterilisation, obsolete, as is the case in Central Burnett in Queensland.

Second variable: High levels of social capital (i.e. personal trust-based amicable relationships) between key participants may facilitate the establishment of AWM, including established trust and communication networks, champions and leadership, such as in Central Burnett (see Box 1). However, it is important that social capital is not located in just some participating groups, as cliques may hinder progress (Pretty 2003).

Third variable: Existing social mechanisms that provide opportunities for monitoring on-farm Queensland fruit fly management, e.g. to keep a check on potential 'free-riders', can facilitate collective action and lower transaction costs. For example, in Central Burnett crop pest consultants making routine field visits enable low-cost monitoring of whether growers are managing Queensland fruit fly. In Riverina, some packing houses insist that their grower suppliers provide proof of Queensland fruit fly management. However, this could be thwarted in times of produce shortage when supply chains ease their grower requirements in order to secure supply.

Fourth variable: The ratio between the number of growers that are keen to pursue AWM and risk contributors who have little incentive to manage Queensland fruit fly (such as several town residents and part-time growers) affects the cost and effort needed to establish AWM. In Central Burnett growers were able to fund town treatments as towns are small relative to the production area. In the Riverina, with the large urban centre of Griffith, this would be less feasible, rendering AWM supporters reliant on awareness-raising to urge town residents to manage Queensland fruit fly on their land.

Policy Implications: The varying profiles of the three case studies illustrate that finding 'one-size-fits-all' local institutions ideal for all AWM programmes is unlikely. The rules relating to how the programme is run, what it involves and what it sets out to achieve are best negotiated locally and tailored to local circumstances. The AWM action situation (Fig. 1) needs to allow for Enticott's (2008) 'spaces of negotiation' to find ways to achieve wide stakeholder support.

\subsection{Principle 2. AWM Needs to be Based on Adaptive Co-management}

The formal requirements for fruit fly AWM (e.g. International Standards for Phytosanitary Measures (ISPMs) and the Queensland fruit fly Code of Practice (Jessup et al. 2007)), could suggest that AWM constitutes standardised 'spaces of prescription' (Enticott 2008), where AWM relies on introducing standard Queensland fruit fly management measures. Local industries' attempts to achieve AWM often involve social, institutional and technical complexity and uncertainty.

Aspects of AWM that involve complexity and uncertainty include its collaborative nature, various on-farm objectives and that not all stakeholders and risk contributors may have incentives to continually manage Queensland fruit fly, as was especially the case in the Riverina. Every local community is different. External expertise should not be privileged at the expense of local knowledge and learning processes rooted in local socio-economic, cultural and political contexts (Kruger 2016a). 
Designing AWM programmes requires a good understanding of the regional Queensland fruit fly situation, including Queensland fruit fly behaviour in and amongst crops, and other local hosts, and this might vary across years with different weather conditions (Clarke et al. 2011).

In the system shown in Fig. 1, an AWM management group needs to continually monitor Queensland fruit fly pressure and adjust local Queensland fruit fly management strategies accordingly. Moreover, achieving market access is complex and uncertain. This was illustrated by the situation in Central Burnett where, despite a successful AWM programme, anticipated access to lucrative markets sensitive to Queensland fruit fly did not occur.

Global experience with a wide range of natural resource management situations has shown that complexity and uncertainty are best surmounted through adaptive comanagement, i.e. a flexible process of 'learning by doing' that draws on different knowledge systems (Armitage et al. 2008). Agricultural innovation systems literature refers to the need for co-producing integrated knowledge between different stakeholder groups to provide a holistic understanding of how to best improve plant protection systems (e.g. Schut et al. 2014). For Queensland fruit fly this includes knowledge on the biology and behaviour of the pest, and its host distribution and phenology. It also requires knowledge on the effectiveness of cultural and other phytosanitary measures and their integration, trade requirements and politics, institutions, risk contributors' motivations and attitudes, and community engagement. Taking these factors into consideration will maximise the chances of designing a successful AWM programme tailored to local conditions.

In the case studies analysed, co-production of knowledge typically occurred within the local management group. Here, participants engaged in social learning, learning from the activities implemented and each other, to continually refine Queensland fruit fly-related management activities. From an adaptive co-management perspective, outcomes need to be closely monitored when changes are introduced to ensure that the system does not loose functionality. Social learning requires sound communication processes that are well-facilitated, both horizontally between local players and vertically across levels as illustrated in Fig. 1. Adaptive co-management was evident in the successful Central Burnett AWM programme (see Box 1).

Adaptive co-management does not offer a 'quick fix', and the investment (transaction cost) to engage with different players and learning processes can be considerable, especially in the early stages of an AWM programme. However, it does offer several important benefits over time (Kruger 2016a):

- Local knowledge of Queensland fruit fly behaviour in the local environment increases

- Management activities are suited to the local region and continually improve

- Local adaptive capacity strengthens, as lessons are learnt about what works and does not work in the local region and under different circumstances

- A common narrative develops between key stakeholders, which is fundamental to developing the much-needed shared vision for AWM

- A more sustainable, fit-for-context and locally-owned initiative is developed. 


\section{Box 1. Adaptive Co-management of Queensland fruit fly in Central Burnett}

The successful Central Burnett AWM programme represents many aspects of adaptive comanagement. Local crop consultants, state government researchers and citrus growers worked closely together on various regional projects from the 1990s, resulting in trust-based amicable relationships. Jointly they decided on research priorities and Queensland fruit fly-related activities for the region, and discussed findings, which subsequently shaped in-field activities. Research was carried out in the region, including in growers' orchards. Growers participated in some research activities, such as when the male annihilation technique was introduced. When AWM was launched in 2003, the local government assisted with community engagement to minimise Queensland fruit fly pressure originating from towns. Other local horticultural industries were engaged in the AWM effort. State government researchers were in close contact with their colleagues responsible for negotiating domestic trade protocols. This assisted in fine-tuning a domestic market access protocol to be accepted by some jurisdictions and be practical for growers to implement. Most growers employed a local crop consultant, with whom they regularly communicated, implying that they had the ear of key decisionmakers, as all crop consultants were management group members. When changes were introduced, such as less intense town treatments, the results were closely monitored to allow for rapid response in case of unfavourable results.

Policy Implications: Adaptive co-management requires a mind-shift from focusing exclusively on implementing Queensland fruit fly management measures such as when the now-restricted chemicals were still available - to implementing measures with the intention of continually learning and adjusting. This is illustrated in Fig. 1 by the two-way arrows between the AWM action situation, the local Queensland fruit fly management strategies and Queensland fruit fly pressure.

Adaptive co-management implies that grower groups need to actively build networks with others, including other growers (or their representatives), experts in Queensland fruit fly behaviour and market access, and community representatives, such as local government. Several of these may involve representatives of organizations that are active in the broader fruit fly management innovation system (Fig. 1).

Several aspects of market access represent 'top-down' elements where growers have little control, such as some trade protocol requirements that are negotiated bilaterally at the federal level. While it is important for those designing AWM programmes to take the technical requirements for market access into consideration as early as possible, it is best for AWM programmes to first focus on achieving Queensland fruit fly suppression. Unmet trade requirements relating to Queensland fruit fly can then be seen as 'bolt-on' components. Government and industry bodies can facilitate access to relevant experts. Other ways in which local industries can be supported are discussed below.

\subsection{Principle 3. Local Industries Need Help to Help Themselves}

An 'ideal type' of knowledge and capabilities that local industries need to access in order to achieve and maintain AWM, was developed during this research. It demonstrates the importance of dedicated staff to oversee and coordinate an AWM programme. In summary, these capabilities are: 
- Programme administration and management - Effective programme implementation, including planning, implementation and monitoring; securing funding, sound financial management, understanding broader institutional requirements, organising and facilitating meetings, and record-keeping.

- Stakeholder interaction - Including achieving a shared local vision, maximising uptake across risk contributors, networking, advocating the programme to key stakeholders, conflict management and supporting growers with recommended practice implementation.

- Understanding Queensland fruit fly behaviour and management - Including general Queensland fruit fly biology and behaviour within the target region, onground management options, and consistently implementing regional Queensland fruit fly management strategies.

- Understanding market access requirements:

- Phytosanitary measure options - including effectiveness and limitations

- Formal market access standards - e.g. relevant ISPMs and Queensland fruit fly Code of Practice; and concepts such as Probit 9 levels, appropriate level of protection and risk management

- Informal aspects and requirements - e.g. market expectations and politics

- Market access application and approval process, including data gathering, and

- Consistent implementation, e.g. monitoring and corrective actions, where needed.

Phase 1 respondents talked about the difficulty of establishing the needed networks to access the knowledge and capabilities required. Some phase 2 interviewees believed that stakeholders at higher levels may easily assume that growers have certain levels of knowledge or capabilities, but in reality, this varies. Interviewees across phases 1 and 2 spoke about issues that added cost and effort to achieve AWM that could be made easier. For example, a high level of government staff turnover contributes to growers struggling to maintain relationships built on a mutual understanding of their local Queensland fruit fly situation, and possible ways forward. Moving forward sometimes depends on joint decision-making between stakeholders from different agencies and 'getting them in one room' is difficult for industry.

Policy Implications: Given the considerable decline in public extension support in Australia, training could be offered to those who are likely to fill at least part of this gap, such as private crop consultants, key growers and other interested local people. This can strengthen local knowledge and capacity on issues such as trade; Queensland fruit fly biology, behaviour and management; and community engagement. However, training without strengthened intermediation between local level actors and other Queensland fruit fly management innovation system actors will do little to encourage 'upward' information flow (see Principle 4). Training can also be a tool to support collaborations across levels by more quickly facilitating in-depth conversations between growers and other stakeholders. Feedback from interviewees also stressed the importance of effective stakeholder coordination between states/territories and between government and industry bodies; minimising staff changes and fostering a client-oriented ethos in government departments. Innovative policy-making can contribute to overcoming local reliance on voluntary approaches (see Principle 5). 


\subsection{Principle 4. AWM Programmes Need Strong Two-way Connectivity with the Broader Queensland fruit fly Management Innovation System}

This research found that local industries easily become disconnected from the broader system. Phase 1 interviewees spoke about the difficulty of establishing networks and finding information and guidance to instigate AWM. Some phase 2 interviewees spoke about inaccessible research findings, as much research is not publicly available, and many growers will not read scientific articles. The disconnect is intensified by the loss of public extension services. The 'grower voice' was considered as underrepresented in national Queensland fruit fly management dialogues. Higher level governance bodies may underestimate local complexities and overestimate the knowledge and abilities of local stakeholders. While peak industry bodies make much contribution to filling this gap, not all growers may see their peak industry body as representing their concerns. Limited resources prevent industry bodies from being involved in all AWM attempts to develop an in-depth understanding of the local issues.

Innovation studies show that successful innovation that results in positive onground change tends to result from a co-evolutionary process involving concurrent technological, social, organizational, and institutional change. As such, growers tend to be partners and entrepreneurs in the innovation system. The prevailing innovation approaches that focus primarily on technology production are increasingly criticized for not achieving intended outcomes often due to a lack of adoption (Klerkx et al. 2012). Instead, a well-functioning innovation system, in this case one that promotes industry-driven Queensland fruit fly AWM, needs to deliver the required institutional, social, and technological change that will maximise the chances for it to flourish (Hekkert et al. 2007). This requires strong feedback loops between local AWM attempts and the broader Queensland fruit fly management innovation system (see Fig. 1).

Policy Implications: Australia's National Fruit Fly Council has made considerable effort to make information on Queensland fruit fly management more accessible since the research was conducted, including online. However, establishing knowledge brokering to enable feedback loops across levels (Fig. 1) can support co-producing integrated knowledge (Kruger 2017). This requires fulfilling key functions to support information flow and collaboration between stakeholder groups (Klerkx et al. 2012), which are easily overlooked as they are often invisible and hard to measure (Klerkx and Leeuwis 2009; Meyer 2010). These key functions are:

- Demand articulation - including assisting local industries with finding a shared vision to identify their technology, knowledge, funding, and policy needs (Klerkx and Leeuwis 2009; Meyer 2010).

- Network establishment - including local horizontal networks and vertical networks with policy-makers and researchers (Klerkx et al. 2012; Meyer 2010).

- Information translation - to connect 'external' information with the local context and growers' existing knowledge in summarized form and language that growers find useful (Klerkx et al. 2012); and local issues are 'translated' to other innovation system players to inform their decision-making (Klerkx and Leeuwis 2009; Meyer 2010). 
- Innovation process management - working towards better arrangements in the multi-actor network, including facilitating cooperation and learning (Klerkx and Leeuwis 2009).

As in Principle 2, collaborations between heterogeneous stakeholders to learn from each other are needed to produce integrated knowledge. Such collaborations represent innovation platforms. Interconnected innovation platforms across levels can be created, e.g. by connecting local AWM groups with multi-stakeholder groups at state and national levels. It enables representation of a stronger 'grower voice' at higher level deliberations and decision-making. The design of such intervention is best negotiated amongst key stakeholders to meet their needs and expectations, ensure maximum buy-in, and to enable a good fit with existing structures. Queensland fruit fly management coordinators at regional, state and national levels can facilitate interconnected innovation platforms and can potentially be co-funded between government and industry.

\subsection{Principle 5. Industry-driven AWM Programmes Need Institutional Adjustment to Share Public Responsibilities and Roles}

A major challenge for industry-driven AWM is dealing with Queensland fruit fly pressure from host plants in town backyards, and on peri-urban and public land. Therefore, public support is vital for AWM success (Dyck et al. 2021). All case studies were reliant on voluntary approaches to address Queensland fruit fly pressure from towns, such as the awareness-raising activities in Young-Harden and Riverina. Currently, legislative power rests predominantly with state governments, but there may be reluctance to introduce enforceable measures that favour industry over other rural groups (NSW 2014). Many local governments have very limited powers to put in place enforceable rules and in the case of study areas they did not have powers to enter backyards without resident permission.

The case studies revealed barriers to behaviour change other than a lack of awareness, e.g. community apathy or recommended Queensland fruit fly management practices not making economic sense. For example, routine sanitation in orchards to remove fallen fruit is another essential AWM component that many growers are reluctant to fund. Other challenges included absentee landholders and derelict orchards.

At least 89 per cent of growers surveyed across all case studies agreed that Queensland fruit fly infestation in towns increases on-farm Queensland fruit fly pressure. However, only 42 per cent of respondents in the Riverina and 40 per cent in Young-Harden had a strong or some belief that regular educational activities would ensure that town residents would adequately manage Queensland fruit fly on their properties. This suggests a limited potential for growers voluntarily contributing to a reliance on awareness-raising activities in towns. 
Another major concern is maintaining commitment and AWM programme funding over the longer term. Establishing an income stream often depends on voluntary contributions from growers. However, Central Burnett demonstrates that this is thwarted by 'free-riding' when some growers refuse to contribute while still benefiting from reduced Queensland fruit fly pressure from towns. This causes others to also 'opt out' of voluntary contributions. For example, 59 per cent of Central Burnet survey respondents said that they would contribute to town treatments only if others contributed too.

Studies about resource governance, involving resource-users taking the lead in setting the rules around resource usage, do not exclude complementary state intervention to back-up the collective action driven by resource users. In various contexts it is seen as important to sustain the trust among resource-users that others will also cooperate, and that a lack of cooperation will not jeopardise individual efforts (Ostrom 2005).

Policy Implications: A recommendation from this work is to apply 'smart regulation', i.e. using complementary policy instruments and behavioural interventions to assist in overcoming the weaknesses of individual instruments, while still capitalising on their strengths. For example, by combining approaches that draw on people's intrinsic motivation to 'do the right thing' with legal instruments that can be enforced and that provide legitimacy to local industry AWM efforts.

Several policy instruments were explored as part of the $\mathrm{PhD}$ research project that were drawn from the case studies, as well as Australia's Landcare Programme for natural resource management, and effective overseas AWM programmes. These instruments could be used in combination with others to ensure that the overall approach is locally tailored:

- Community education and awareness-raising - if well implemented, this approach can influence people who have an intrinsic motivation to manage the pest, such as households valuing their backyard produce. The investment needed to sustain effective awareness campaigns are easily under-estimated. However, such campaigns will do little to overcome behavioural change barriers beyond a lack of awareness (Curtis et al. 2014).

- Broad-scale state regulation enforcing Queensland fruit fly management on all land - while this can be applied consistently across risk contributors, it is very costly to monitor and enforce. There are also moral challenges, such as when landholders are physically or financially unable to manage Queensland fruit fly. Magistrate courts easily misunderstand the level of Queensland fruit fly control required and have rejected cases brought for prosecution (personal communication, state government interviewee, 24 September 2013).

- Co-opting local stakeholders to support better implementation of government powers - including authority to enter private property and/or prosecute noncompliant landowners. This lessens the monitoring and enforcement burden on state governments. It is applied in the US states of Oregon and Washington, for example under the 2011 Washington Code (Washington State Legislature 2011). However, some authorities may be reluctant to favour industry needs over those of other community groups. 
- Devolved power to enable industry, in partnership with local communities, to devise rules appropriate for the local context - including possibly allowing enforcement as a 'back-up' mechanism. This aligns most closely with the underlying principles contained in much of the community engagement literature that values community involvement in the decision-making of issues affecting them. However, results elsewhere have been mixed in natural resource management (Berkes 2010). Potential adversarial effects include conflict and 'power grabs' by some groups (Berkes 2010). Dealing with uninformed people trying to influence the programme is difficult (Dyck et al. 2021). Such approaches tend to require considerable investment and skill.

- Legislated cost-recovery structures - A legislated income-stream can facilitate industry and other appropriate local stakeholders to implement on-going and reliable pest treatments in Queensland fruit fly risk areas in combination with community awareness activities. It can come from mandatory contribution from growers, the state and possibly town residents, such as in the successful OKSIR programme for codling moth control in British Columbia, Canada (Dyck et al. 2021; Nelson et al., this volume). However, such schemes could encounter resistance from those expected to contribute unless the contributions are adjusted to be proportionate to the expected benefits.

\section{CONCLUSION}

The research reported here explored whether industry-driven fruit fly area-wide management is feasible, with special focus on Queensland fruit fly AWM programmes in New South Wales and Queensland, Australia. This manuscript contains a summary of a social science $\mathrm{PhD}$ project that involved an investigation of three case studies of AWM programmes (or attempts thereof), a grower survey and interviews with people operating in the broader Queensland Fruit Fly management innovation system.

It found that the feasibility of industry-driven AWM depends on social and institutional factors at the local level and within the broader Queensland fruit fly management innovation system. Advantageous local factors include a favourable social profile, such as growers with relatively homogeneous on-farm goals and high levels of social capital, as well as the application of adaptive co-management. AWM programmes need to be adjusted to the local context, with market access requirements seen as 'bolt-on' components.

An enabling environment for industry-driven AWM requires a broader innovation system that is responsive to the needs of local industries. This requires strong twoway information flow between local programmes and other players in the innovation system, such as policy-makers and technology developers, which can be supported through knowledge-brokers and vertically interconnected innovation platforms. 'Smart regulation' can assist local industries to overcome the limitations of voluntary approaches (such as depending on awareness-raising and education alone), by influencing people through a combination of policy instruments tailored to local conditions. 


\section{REFERENCES}

Armitage, D. R., R. Plummer, F. Berkes, R. I. Arthur, A. T. Charles, I. J. Davidson-Hunt, A. P. Diduck, N. C. Doubleday, D. S. Johnson, M. Marschke, P. McConney, E. W. Pinkerton, and E. K. Wollenberg. 2008. Adaptive co-management for social-ecological complexity. Frontiers in Ecology and the Environment 7: 95-102.

Berkes, F. 2010. Devolution of environment and resources governance: Trends and future. Environmental Conservation 37: 489-500.

Clarke, A. R., K. S. Powell, C. W. Weldon, and P. W. Taylor. 2011. The ecology of Bactrocera tryoni (Diptera: Tephritidae): What do we know to assist pest management? Annals of Applied Biology 158: 26-54.

Curtis, A., H. Ross, G. R. Marshall, C. Baldwin, J. Cavaye, C. Freeman, A. Carr, and G. J. Syme. 2014. The great experiment with devolved natural resource management governance: Lessons from community engagement in Australia and New Zealand since the 1980s. Australasian Journal of Environmental Management 21: 175-199.

Dominiak, B. C., and J. H. Ekman. 2013. The rise and demise of control options for fruit fly in Australia. Crop Protection 51: 57-67.

Dyck, V. A., J. Reyes Flores, M. J. B. Vreysen, E. E. Regidor Fernández, B. N. Barnes, M. Loosjes, P. Gómez Riera, T. Teruya, and D. Lindquist. 2021. Management of Area-Wide Integrated Pest Management programmes that integrate the Sterile Insect Technique, pp. 781-814. In V. A. Dyck, J. Hendrichs, and A. S. Robinson (eds.), Sterile Insect Technique - Principles and practice in Area-Wide Integrated Pest Management. Second Edition. CRC Press, Boca Raton, Florida, USA.

Enticott, G. 2008. The spaces of biosecurity: Prescribing and negotiating solutions to bovine tuberculosis. Environment and Planning A 40: 1568-1582.

(FAO) Food and Agriculture Organization of the United Nations. 2016. Establishment of pest free areas for fruit flies (Tephritidae). International Standard for Phytosanitary Measures (ISPM) No. 26. International Plant Protection Convention. FAO, Rome, Italy.

(FAO) Food and Agriculture Organization of the United Nations. 2018. Systems approach for pest risk management of fruit flies (Tephritidae). International Standard for Phytosanitary Measures (ISPM) No. 35. International Plant Protection Convention. FAO, Rome, Italy.

Hekkert, M. P., R. A. Suurs, S. O. Negro, S. Kuhlmann, and R. E. Smits. 2007. Functions of innovation systems: A new approach for analysing technological change. Technological Forecasting and Social Change 74: 413-432.

Higgins, V., M. Bryant, M. Hernández-Jover, C. McShane, L. and Rast. 2016. Harmonising devolved responsibility for biosecurity governance: The challenge of competing institutional logics. Environment and Planning A 48(6): 1131-1151.

Jessup, A. J., B. Dominiak, B. Woods, C. P. F. de Lima, A. Tomkins, and C. J. Smallridge. 2007. Area-wide management of fruit flies in Australia, pp. 685-697. In M. J. B. Vreysen, A. S. Robinson, and J. Hendrichs (eds.), Area-wide control of insect pests. From research to field implementation. Springer, Dordrecht, The Netherlands.

Klerkx, L., and C. Leeuwis. 2009. Establishment and embedding of innovation brokers at different innovation system levels: Insights from the Dutch agricultural sector. Technological Forecasting and Social Change 76: 849-860.

Klerkx, L., M. Schut, C. Leeuwis, and C. Kilelu. 2012. Advances in knowledge brokering in the agricultural sector: Towards innovation system facilitation. Institute of Development Studies Bulletin 43: 53-60.

Kruger, H. 2016a. Adaptive co-management for collaborative commercial pest management: The case of industry-driven fruit fly area-wide management. International Journal of Pest Management 62: 336347.

Kruger, H. 2016b. Designing local institutions for cooperative pest management to underpin market access: The case of industry-driven fruit fly area-wide management. International Journal of the Commons 10: 176-199.

Kruger, H. 2017. Creating an enabling environment for industry-driven pest suppression: The case of suppressing Queensland fruit fly through area-wide management. Agricultural Systems (Issue C) 156: 139-148.

Kruger, H. 2018. The social and institutional aspects of industry-driven fruit fly area-wide management in Australian horticultural industries, Australian National University and Charles Darwin University, $\mathrm{PhD}$ thesis, $293 \mathrm{pp}$. 
Meyer, M. 2010. The rise of the knowledge broker. Science Communication 32: 118-127.

(NFFC) National Fruit Fly Council. 2016. Area wide management. Plant Health Australia. Canberra, Australia.

(NSW) New South Wales Trade and Investment. 2014. Management of fruit flies in New South Wales. In Plant Biosecurity \& Product Integrity. NSW Government, Sydney, Australia. 5 pp.

Ostrom, E. 2005. Understanding institutional diversity. Princeton Paperbacks. Princeton University Press, Princeton, New Jersey, USA. 376 pp.

(PBCRC) Plant Biosecurity Cooperative Research Centre. 2015. National Fruit Fly Research, Development and Extension Plan. Canberra, Australia. 56 pp.

(PHA) Plant Health Australia. 2008. Draft national fruit fly strategy. A Primary Industry Health Committee Commissioned Project. Plant Health Australia, Canberra, Australia. 64 pp.

Pretty, J. 2003. Social capital and the collective management of resources. Science 302(5652): 19121914.

Schut, M., J. Rodenburg, L. Klerkx, A. van Ast, and L. Bastiaans. 2014. Systems approaches to innovation in crop protection. A systematic literature review. Crop Protection 56: 98-108.

Washington State Legislature. 2011. Horticultural Pest and Disease Board. In Washington State Legislature, Title 15 Chapter 15.9. Olympia, Washington, USA. 